\title{
Balancing risk versus reward in isolated repair of severe tricuspid regurgitation
}

Chris C. Cook, MD, Muhammed Salman, MD, Lawrence M. Wei, MD, Harold G. Roberts, MD, and

Vinay Badhwar, MD

From the Department of Cardiovascular and Thoracic Surgery, West Virginia University, Morgantown, WVa.

Disclosures: Authors have nothing to disclose with regard to commercial support.

Received for publication April 14, 2018; accepted for publication April 16, 2018; available ahead of print May 11, 2018.

Address for reprints: Vinay Badhwar, MD, Department of Cardiovascular and Thoracic Surgery, West Virginia

University, 1 Medical Center Drive, Morgantown, WV 26506 (E-mail: vinay.badhwar@wvumedicine.org).

J Thorac Cardiovasc Surg 2018;156:658-9

$0022-5223 / \$ 36.00$

Copyright (c) 2018 by The American Association for Thoracic Surgery

https://doi.org/10.1016/j.jtcvs.2018.04.069

In the current issue of The Journal of Thoracic and Cardiovascular Surgery, Takamatsu and coauthors ${ }^{1}$ report a case of severe chronic tricuspid regurgitation (TR) due to anterior leaflet flail in a remote drug user, in whom they used the posterior leaflet to repair the defect. The authors found the anterior leaflet defect to be proximate to the posterior leaflet, which was transposed along with its associated chordae, followed by a modified Kay bicuspidization suture compression and reduction rigid ring annuloplasty. Technical success was achieved with trace to mild residual TR by postoperative and 1-month echocardiography, and 1year freedom from symptoms but without available imaging.

Isolated surgeries for TR have historically been rare. Perhaps this is in part because of the misconception that medical management of this tolerated lesion might indefinitely provide symptom recovery with minimal sequelae. Perhaps this because of the interpretation of an elevated mortality risk thus preventing timely referral. Recent data indicate that isolated tricuspid valve surgeries are associated with a mortality risk of $7 \%$ to $10 \%$, particularly in functional TR. ${ }^{2,3}$ Whereas repair of concomitant TR at the time of mitral surgery does not increase mortality, reoperations for uncorrected isolated TR have been historically associated with up to $35 \%$ risk of mortality. ${ }^{4,5}$ The current case ${ }^{1}$ illustrates that severe chronic primary TR produces significant disability due to the long-term sequelae of right ventricular remodeling, congestive hepatopathy, renal insufficiency, and profound lower extremity edema. Isolated tricuspid valve replacement is associated with higher surgical mortality than tricuspid repair. ${ }^{2,3}$ Tricuspid valve replacement is less attractive in young patients because of the high incidence of thrombosis of mechanical valves and the high rate of bioprosthetic valve failure. Because of these inherent risks, the authors ${ }^{1}$ are thus to be commended for their recognition of the need for immediate surgical intervention and for their efforts to use a durable repair.

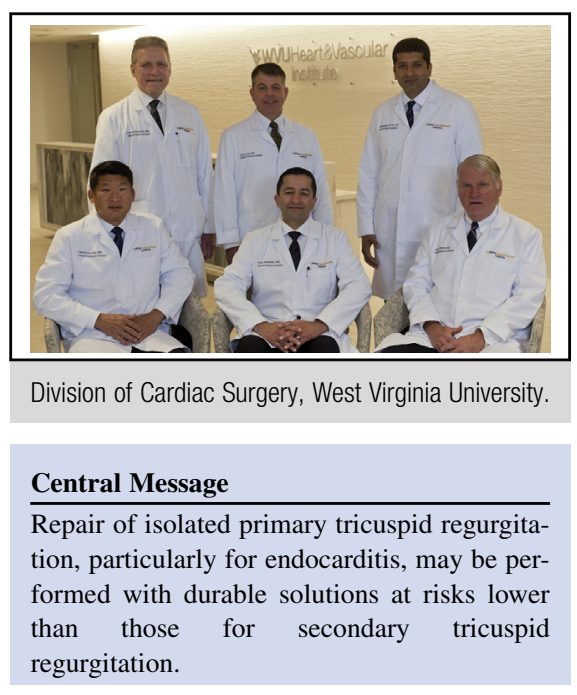

See Article page 655 .
Surgery for isolated TR is rapidly increasing. The national opioid epidemic in the United States has led to a marked increase in bacterial endocarditis requiring surgical intervention at an unprecedented level. The epicenter of this crisis is in the Appalachian region of West Virgina. ${ }^{6,7}$ Once a rare event, isolated tricuspid surgeries for intravenous drug-associated endocarditis in this region of the United States are now at least a weekly occurrence. With an aggressive approach to lesions with opportunistic organisms, embolic complications, or large vegetations, isolated tricuspid valve repair is often possible by using reconstructive techniques like those used by the authors ${ }^{1}$ and with outcomes that are often superior to those reported for functional TR. ${ }^{8}$ Many familiar techniques used in mitral valve repair have been successfully applied to tricuspid lesions including the use of autologous pericardium for leaflet reconstruction. Because many of these unfortunate patients suffering from opioid addiction are emaciated and at increased risk for sternal complications, experience with these techniques have made them ideally suited to a mini thoracotomy approach facilitated by peripheral perfusion.

Polytetrafluoroethylene neochord implantation primarily, or to support autologous pericardium, are increasingly being used in the tricuspid position but not without specific technical challenges. The papillary muscles of the right ventricle $(\mathrm{RV})$ are often less robust and more variable 
than their left ventricular counterparts and the thin RV makes it more prone to dynamic changes to volume and remodeling over time. These factors might make the application and sizing of neochords technically more difficult than when applied to the mitral valve. Native primary chords are often seen emanating directly from the RV wall and septum, especially the septal leaflet, and implanting neochords in this location often makes adjusting length more reproducible and might obviate the concern for recurrent prolapse due to late RV remodeling. Native chordal or leaflet tissue transposition, particularly using the posterior leaflet as shown in this case report ${ }^{1}$ is another option to mitigate the sizing issues of neochords, provided the tissue is available in cases of acute endocarditis.

For young patients with severe TR, the higher mortality rate and prosthesis liabilities associated with tricuspid valve replacement emphasize the need for techniques to achieve durable repair. This need is most pressing for patients suffering from intravenous drug-associated tricuspid endocarditis who are exposed to an inherent risk of recidivism. As experience with these repair techniques increase and short-term outcomes with isolated tricuspid surgeries improve, reproducibility and long-term durability must be confirmed.

\section{References}

1. Takamatsu M, Hirotani T, Ohtsubo S, Takeuchi S. Tricuspid valve repair: chordae transposition of the entire posterior leaflet for extensive anterior leaflet prolapse. $J$ Thorac Cardiovasc Surg. 2018;156:655-7.

2. Alqahtani F, Berzingi CO, Aljohani S, Hijazi M, Al-Hallak A, Alkhouli M Contemporary trends in the use and outcomes of surgical treatment of tricuspid regurgitation. J Am Heart Assoc. 2017;6:e07597.

3. Zack CJ, Fender EA, Chandrashekar P, Reddy YN, Bennett CE, Stulak JM, et al National trends and outcomes in isolated tricuspid valve surgery. J Am Coll Cardiol. 2017;70:2953-60.

4. Badhwar V, Rankin JS, He M, Jacobs JP, Furnary AP, Fazzalari FL, et al. Performing concomitant tricuspid valve repair at the time of mitral valve operations is not associated with increased operative mortality. Ann Thorac Surg. 2017; 103:587-93.

5. Bernal JM, Morales D, Revuelta C, Llorca J, Gutiérrez-Morlote J, Revuelta JM Reoperations after tricuspid valve repair. J Thorac Cardiovasc Surg. 2005; 130: 498-503.

6. Ferraris VA, Sekela ME. Missing the forest for the trees: the world around us and surgical treatment of endocarditis. J Thorac Cardiovasc Surg. 2016;152:677-80.

7. Badhwar V, Wei LM, Rankin JS. Seeing the entire forest in endocarditis. J Thorac Cardiovasc Surg. 2016;152:681-2.

8. Dawood MY, Cheema FH, Ghoreishi M, Foster NW, Villanueva RM, Salenger R, et al. Contemporary outcomes of operations for tricuspid valve infective endocarditis. Ann Thorac Surg. 2015;99:539-46. 